\title{
Violence and Warfare in Prehistoric Japan
}

\section{Tomomi Nakagawa ${ }^{1, *}$, Hisashi Nakao², Kohei Tamura $^{3}$, Yui Arimatsu3 ${ }^{3}$ Naoko Matsumoto', Takehiko Matsugi ${ }^{4}$}

1 Graduate School of Humanities and Social Sciences, Okayama University, 3-1-1 Tsushimanaka, Kita-ku, Okayama 700-0082, Japan

${ }^{2}$ Department of Global and Science Studies, Yamaguchi University, Japan

${ }^{3}$ Frontier Research Institute for Interdisciplinary Sciences, Tohoku University, Japan

${ }^{4}$ National Museum of Japanese History, Japan

"Author for correspondence (tomomi.n@s.okayama-u.ac.jp)

The origins and consequences of warfare or largescale intergroup violence have been subject of long debate. Based on exhaustive surveys of skeletal remains for prehistoric hunter-gatherers and agriculturists in Japan, the present study examines levels of inferred violence and their implications for two different evolutionary models, i.e., parochial altruism model and subsistence model. The former assumes that frequent warfare played an important role in the evolution of altruism and the latter sees warfare as promoted by social changes induced by agriculture. Our results are inconsistent with the parochial altruism model but consistent with the subsistence model, although the mortality values attributable to violence between hunter-gatherers and agriculturists were comparable.

\section{Keywords}

archaeology; warfare; parochial altruism; human skeletal remains; Japan

\section{Introduction}

The "parochial altruism model," or the evolution of altruism (intra-group cooperation) driven by warfare (large-scale intergroup violence), proposed by Samuel Bowles and colleagues (Bowles, 2009; Choi \& Bowles, 2007), has accelerated arguments on the origin of warfare and its evolutionary role in many fields, including psychology (Yamagishi \& Mifune, 2016), biology (Rusch, 2014), and anthropology (Fry \& Söderberg, 2013). Bowles's model, based on empirical evidence for the ubiquity of violence among contemporary and prehistoric huntergatherers, assumes that groups with more altruists are more likely to defeat other groups, so the high frequency of warfare could have promoted the evolution of altruism (Bowles, 2009; Pinker, 2011).

Some have doubted the parochial altruism model because of the biased archaeological and ethnographic data used in the studies supporting it (Ferguson, 2013; Fry
\& Söderberg, 2013), and emphasized rather the importance of exhaustive surveys. Nakao et al. (2016a,b) carried out such a survey on skeletal remains of prehistoric huntergatherers in Japan, reporting a much lower mortality rate attributable to violence compared to previous studies (e.g., Bowles, 2009), along with an absence of large-scale violence, supporting doubts about the parochial altruism model.

Anthropologists and archaeologists have proposed a different model of warfare, in which subsistence strategy plays an important role: Agriculturists are more likely to engage in warfare than hunter-gatherers because agriculture can sustain population growth and thereby increase demand for arable land, eventually fostering competition over such land (Sahara, 1999).

Note that the two models are neither mutually exclusive nor competing. The subsistence model explains the origin of warfare, i.e, why did warfare begin, and the parochial altruism model refers to the frequency and consequence of warfare, i.e., how could warfare or intergroup conflicts promote altruism. Our studies try to test the two models that are independent but based on the prehistoric data of violence and warfare.

In the present study we examine the issue of warfare using data for human skeletal remains in Japan. Results from Japanese archaeology are useful for such an examination because of the large amount of data on human remains of prehistoric hunter-gatherers in the Jomon and agriculturists in the ensuing Yayoi periods. Based on evidence for warfare such as weapons and fortifications, Japanese archaeologists have traditionally claimed a Yayoi period origin of warfare in line with the subsistence model (e.g., Sahara, 1986). However, this model is yet to be examined quantitatively. In what follows, we first calculate the fraction of injured individuals among skeletal remains of the Yayoi period, to assess the rate of mortality attributable to violence as a proxy for the incidence of warfare. We then compare the rate of violent mortality with similar data for the Jomon period. A significantly higher level of mortality attributable to violence in the Yayoi period would support the subsistence model.

\section{Material and Methods}

Values for violent mortality in the Jomon period were taken from Nakao et al. (2016a,b). For the Yayoi period, we compiled a data set based on published site reports referenced in exhaustive lists of literature on human skeletal remains of that period in the Japanese archipelago south of Hokkaido (Comprehensive Database of Archaeological Site Reports in Japan; Department of Anatomy 2 of Kyushu University, 1988; Ikeda, 1981, 1986; Ikeda \& Matsumura, 1992; Ikeda \& Nakahashi, 2000, 2001; Nara, Saeki, Hagiwara, \& Sawada 2016a,b), and on literature focusing on injured individuals in those periods (Fujiwara, 2004; Hashiguchi, 2007). We included 
Table 1. Summary of data on all human remains from the Jomon and Yayoi periods in Japan.

\begin{tabular}{|c|c|c|c|c|c|c|c|c|c|c|}
\hline $\begin{array}{l}\text { Phase } \\
\text { (Jomon) }\end{array}$ & Total & Adults & ID & $\begin{array}{l}\text { ID } \\
\text { excluding } \\
\text { children }\end{array}$ & Adults* & ID* & $\begin{array}{l}\text { ID } \\
\text { excluding } \\
\text { children* }\end{array}$ & $\begin{array}{l}\text { ID/ } \\
\text { Total }\end{array}$ & $\begin{array}{l}\text { ID } \\
\text { excluding } \\
\text { children/ } \\
\text { adults }\end{array}$ & $\begin{array}{l}\text { ID } \\
\text { excluding } \\
\text { children*/ } \\
\text { adults* }\end{array}$ \\
\hline Initial & 113 & 39 & 1 & 1 & 28 & 1 & 1 & $0.88 \%$ & $2.56 \%$ & $3.57 \%$ \\
\hline Early & 216 & 117 & 0 & 0 & 98 & 0 & 0 & $0.00 \%$ & $0.00 \%$ & $0.00 \%$ \\
\hline Middle & 371 & 172 & 5 & 5 & 97 & 3 & 3 & $1.35 \%$ & $2.91 \%$ & $3.09 \%$ \\
\hline Late & 944 & 470 & 7 & 7 & 398 & 6 & 6 & $0.74 \%$ & $1.49 \%$ & $1.51 \%$ \\
\hline Final & 932 & 471 & 10 & 10 & 430 & 9 & 9 & $1.07 \%$ & $2.12 \%$ & $2.09 \%$ \\
\hline Total & 2576 & 1269 & 23 & 23 & 1051 & 19 & 19 & $0.89 \%$ & $1.81 \%$ & $1.81 \%$ \\
\hline $\begin{array}{l}\text { Phase } \\
\text { (Yayoi) }\end{array}$ & Total & Adults & ID & $\begin{array}{l}\text { ID } \\
\text { excluding } \\
\text { children }\end{array}$ & Adults* & ID* & $\begin{array}{l}\text { ID } \\
\text { excluding } \\
\text { children* }\end{array}$ & $\begin{array}{l}\text { ID/ } \\
\text { Total }\end{array}$ & $\begin{array}{l}\text { ID } \\
\text { excluding } \\
\text { children/ } \\
\text { adults }\end{array}$ & $\begin{array}{l}\text { ID } \\
\text { excluding } \\
\text { children*/ } \\
\text { adults* }\end{array}$ \\
\hline Incipient & 27 & 25 & 6 & 6 & 10 & 5 & 5 & $22.22 \%$ & $24.00 \%$ & $50.00 \%$ \\
\hline Early & 233 & 156 & 7 & 7 & 115 & 1 & 1 & $3.00 \%$ & $4.49 \%$ & $0.87 \%$ \\
\hline Middle & 2347 & 1794 & 70 & 66 & 1541 & 53 & 49 & $2.98 \%$ & $3.68 \%$ & $3.18 \%$ \\
\hline Late & 691 & 420 & 17 & 17 & 270 & 15 & 15 & $2.46 \%$ & $4.05 \%$ & $5.56 \%$ \\
\hline Total & 3298 & 2395 & 100 & 96 & 1936 & 74 & 70 & $3.03 \%$ & $4.01 \%$ & $3.62 \%$ \\
\hline
\end{tabular}

See Nakao et al. (2016a) for the actual dates of the phases in the Jomon period. The Yayoi period is subdivided into four phases: Incipient (800-600 cal BC), Early (600-300 cal BC), Middle (300 cal BC-AD 50), and Late (AD 50-250). Skeletal remains which cannot be clearly categorized to a single phase are excluded. ID = injured individuals.

* Excluding data for sites with human skeletal remains of less than ten individuals.

in our data set the presence or absence of injury, sex, age (adult/child), site, and period for each individual (see the electronic supplementary material for more details).

Following previous research (Bowles, 2009; Nakao et al., 2016a), we calculated the percentage of injured individuals, as an estimate of the rate of violent mortality, in each of the following three ways: Method 1, among the total population including children and individuals whose sexes and ages are unknown; Method 2, among all adults; and Method 3, among adults after excluding sites where the number of individuals is less than ten. We then conducted chi-squared tests of comparisons of these values with those similarly obtained for Jomon data.

Note that the methods for collecting and calculating the data are the same with Bowles (2009). The data set is not selective and includes all of the available information. The definition of the injured individuals could include injuries not only due to warfare but also due to homicide like Bowles (2009) since it is difficult to distinguish them especially in archaeological data (see the electronic supplementary material for more details). Thus the rate of violence observed in archaeological data is not directly comparable to that in ethnography, but if the former is low, it would indirectly suggest that warfare could not have been prevalent.

\section{Results}

The average violent mortality estimates calculated for each phase and across the entire Jomon and Yayoi periods are indicated in Table 1 (see the supplementary material for more details).

The violent mortality values calculated following Methods $1-3$ in the Yayoi period $(0 \%-5.56 \%)$ are comparable with those in the Jomon period $(0 \%-3.57 \%)$ and much lower than those from previous studies (Bowles, 2009; Pinker, 2011), with the exception of the Incipient phase of the Yayoi period $(22.22 \%-50 \%)$. This is probably due to small sample size: Human skeletal remains were found in only four sites in the phase, though the Itoku site in Kochi prefecture has five injured individuals among ten remains found in total (see Table S1).

Chi-squared tests showed statistically significant differences between the values of the Jomon and Yayoi periods, suggesting a higher frequency of violence in the Yayoi, for each way of calculation: Method $1, \chi^{2}(1, N=$ $5,874)=32.286, p<.001$; Method 2, $\chi^{2}(1, N=3,664)=$ $12.729, p<.001$; and Method 3, $\chi^{2}(1, N=2,987)=7.702, p$ $=.0055$.

\section{Discussion}

The present study made an exhaustive survey of archaeological data on human skeletal remains of the Yayoi period in Japan, to examine levels of mortality attributable to violence as a potential indicator of warfare. The results were then compared with similar values previously reported for the Jomon period by Nakao et al. $(2016 a, b)$. It is worth noting first the relatively low rate of violent mortality inferred for the Yayoi period, much lower than those from previous cross-cultural studies (e.g., Bowles, 2009). Although we must interpret such a result with caution, due to difficulties in estimating the cost and benefits of altruistic behavior in Bowles's (2009) model, the Japanese case overall suggests a level of violence too low to exert selective pressure for the evolution of altruism.

Our analysis nevertheless showed statistically significantly higher levels of violent mortality for the Yayoi than the Jomon periods. This result is consistent 
with the subsistence model and the traditional view that warfare in Japan began in the Yayoi period. In fact, the earliest findings of fortification and weapons, which can be considered as evidence of warfare (e.g., Ferguson 2013), were from sites in the Yayoi period (Sahara, 1986).

It is possible that the level of mortality attributable to violence in the Yayoi period is not representative of prehistoric agricultural societies. Indeed, the degree of violent mortality calculated by Method 1 (104/3428 $=3.03 \%$ ) for the Yayoi period is lower than that of Mesolithic Europe $(80 / 2055=3.89 \%)$, which includes postPleistocene, pre-agricultural societies of various levels of complexity (N. Nakagawa, H. Nakao, unpublished data, Title: A critical evaluation of recent violence and warfare arguments with reference to data from human skeletal remains in Mesolithic Europe. Data set available: http://hisashinakao.com/data/ (last accessed on 25 March 2017) (in Japanese)). This is possibly because we have oversimplified the relationship between agriculture and warfare. Agriculture potentially alters various aspects of human life including settlement patterns, social complexity, and ideology. Due to the lack of data, we were unable to identify which of these aspects played a crucial role in promoting violence in the Yayoi period. As warfare has been claimed more common in Europe during the prehistoric agricultural Neolithic period than in the preceding Mesolithic (Ferguson, 2013), agriculture was possibly an important factor affecting warfare in the European case. But the major factors behind warfare in Neolithic Europe and Yayoi Japan may well differ. Besides, it is likely that the effect of agriculture on the incidence of warfare resulted from interactions between agriculturally induced social changes and region-specific factors. The intensity of competition over land, for example, will of course depend on environmental and climatic conditions. Accordingly, investigations of mortality attributable to violence in hunter-gatherer versus agriculturist societies within a single region warrant further research, and crosscultural studies based on data from several regions require careful interpretation.

Our study has further limitations. First, we focused only on human skeletal remains. Although important as direct evidence of violence, the survival rate of skeletal matter is more severely affected by soil conditions than other archaeological materials. Second, the study is not explanatory but merely descriptive. A possible direction for future research is to conduct a mathematical analysis of the relationship between mortality based on human skeletal remains on the one hand, with other relevant archaeological evidence and possibly related factors for warfare, such as demography and social complexity.

\section{Acknowledgment}

This work is supported by The Konosuke Matsushita Memorial Foundation Research Grant, JSPS aid for "TopicSetting Program to Advance Cutting-Edge Humanities and Social Sciences Research: Area Cultivation," Suntory Foundation Research Grants, JSPS Grant-in-Aid (No. 16K16685, No. 16H06615), and "Program for Fostering Researchers for the Next Generation" (JST). We are grateful to Satoru Nakazono for his advice and comments on the chronology of Yayoi burials. We also appreciate the careful work by librarians at Yamaguchi University, especially Yuko Wada, for collecting relevant site reports.

\section{Supplementary material}

Electronic supplementary material is available online.

\section{References}

Bowles, S. (2009). Did warfare among ancestral huntergatherers affect the evolution of human social behaviors? Science, 324, 1293-1298. (doi: 10.1126/ science.1168112)

Choi, J.-K., \& Bowles, S. (2007). The coevolution of parochial altruism and war. Science, 318, 636-640. (doi: 10.1126/science.1144237)

Comprehensive Database of Archaeological Site Reports in Japan. Retrieved from http://sitereports.nabunken. go.jp/en (last accessed on 24 March 2017) Nara: Nara National Research Institute for Cultural Properties. (in Japanese)

Department of Anatomy 2 of Kyushu University (Ed.). (1988). Nihon minzoku, bunka no seisei: Kyushu daigaku igakubu kaibogaku daini kouza syozo kojinkotsu siryo shusei [Japan and the generation of culture: human remains collected by the Department of Anatomy 2 of Kyushu University]. Tokyo: Rokko Shuppan. (in Japanese)

Ferguson, B. F. (2013). The prehistory of war and peace in Europe and the Near East. In. D. P. Fry (Ed.), War, peace, and human nature: the convergence of evolutionary and cultural views (pp. 191-241). Oxford: Oxford University Press.

Fry, D. P., \& Söderberg, P. (2013). Lethal aggression in mobile forager bands and implications for the origins of war. Science, 341, 270-273. (doi: 10.1126/ science.1235675)

Fujiwara, S. (2004). Tactics in fighting during the Yayoi period. Nihon Kokogaku (Journal of the Japanese Archaeological Association), 11(18), 37-52. (doi: 10.11215/nihonkokogaku1994.11.18_37) (in Japanese)

Hashiguchi, T. (2007). Yayoi jidai no tatakai: tatakai no jittai to kenryoku kiko no seisei [Warfare in the Yayoi period: the reality of warfare and generation of power structure]. Tokyo: Yuzankaku. (in Japanese)

Ikeda, J. (1981). Bibliography of human skeletal remains excavated in Japan (1945-1979) (2). Journal of the Anthropological Society of Nippon, 89, 505-514. (doi: 10.1537/ase1911.89.505) (in Japanese)

Ikeda, J. (1986). Bibliography (1980-1984) of human skeletal remains unearthed in Japan. In. Committee for Celebrating the Retirement of Jiro Ikeda (Ed.), Ikeda jiro kyoju gyoseki shu [Collected works by Jiro Ikeda] (pp. 35-72). Kyoto: Kyoto University. (in Japanese)

Ikeda, J., \& Matsuda, H. (1992). Bibliography (1985-1989) of human skeletal remains excavated in Japan. Journal of the Anthropological Society of Nippon, 100, 359383. (doi: 10.1537/ase1911.100.359) (in Japanese)

Ikeda, J., \& Nakahashi, T. (2000). Bibliography (19901994) of human skeletal remains unearthed in Japan. Anthropological Science (Japanese Series), 108, 101131. (doi: 10.1537/asj1998.108.101) (in Japanese)

Ikeda, J., \& Nakahashi, T. (2001). Bibliography (19952000) of human skeletal remains unearthed in Japan. Anthropological Science (Japanese Series), 109, 9-42. (in Japanese) 
Nakao, H., Tamura, K., Arimatsu, Y., Nakagawa, T., Matsumoto, N., \& Matsugi, T. (2016a). Violence in the prehistoric period of Japan: the spatio-temporal pattern of skeletal evidence for violence in the Jomon period. Biology Letters, 12, 20160028. (doi: 10.1098/ rsbl.2016.0028)

Nakao, H., Tamura, K., Arimatsu, Y., Nakagawa, T., Matsumoto, N., \& Matsugi, T. (2016b). Correction to: "Violence in the prehistoric period of Japan: the spatio-temporal pattern of skeletal evidence for violence in the Jomon period.” Biology Letters, 12, 20160847. (doi: 10.1098/rsbl.2016.0847)

Nara, T., Saeki, F., Hagiwara, Y., \& Sawada, S. (2016a). Bibliography (2001-2005) of human skeletal remains unearthed in Japan. Anthropological Science (Japanese Series), 124, 19-47. (doi: 10.1537/asj.124.19) (in Japanese)

Nara, T., Saeki, F., Hagiwara, Y., \& Sawada, S. (2016b). Bibliography (2006-2016) of human skeletal remains unearthed in Japan. Anthropological Science (Japanese Series), 124, 93-148. (doi: 10.1537/asj.124.93) (in Japanese)

Pinker, S. (2011). The better angels of our nature: why violence has declined. New York: Viking.

Rusch, H. (2014). The evolutionary interplay of intergroup conflict and altruism in humans: a review of parochial altruism theory and prospects for its extension. Proceedings of the Royal Society B: Biological Sciences, 281, 20141539. (doi: 10.1098/rspb.2014.1539)

Sahara, M. (1986). Kachiku, dorei, obo, senso [Cattles, slaves, kingly tombs and warfare: Japan in the world]. Rekishi Kagaku, 103, 1-17. (in Japanese)

Sahara, M. (1999). Nihon, sekai no senso no kigen [Origin of warfare in Japan and the world]. In. K. Fukui, \& H. Harunari (Eds.), Jinrui ni totte tatakai towa (1): tatakai no shinka to kokka no seisei [Evolution of warfare and state formation] (pp. 58-100). Tokyo: Toyo Shorin. (in Japanese)

Yamagishi, T., \& Mifune, N. (2016). Parochial altruism: does it explain modern human group psychology? Current Opinion in Psychology, 7, 39-43. (doi: 10.1016/j.copsyc.2015.07.015) 